DOI: http://doi.org/10.21698/simi.2018.fp54

\title{
THE USE OF CORTICOLOUS LICHEN SPECIES TO ASSESS THE LEVEL OF AIR POLLUTION WITH HEAVY METALS
}

Dorian-Gabriel Neidoni ${ }^{1,3}$, Ladislau Andres ${ }^{1}$, Valeria Nicorescu ${ }^{1}$, Carol Blaziu Lehr ${ }^{2}$, Elena Bucur $^{2}$, Adrian Sinitean ${ }^{3}$

${ }^{1}$ National Research and Development Institute for Industrial Ecology- ECOIND Timisoara Subsidiary, 115 Bujorilor, 300431, Timisoara, ecoind.tm@gmail.com, Romania

${ }^{2}$ National Research and Development Institute for Industrial Ecology - ECOIND, 71-73 Drumul Podu Dambovitei, district 6, 060652, Bucharest, Romania

${ }^{3}$ West University of Timisoara, Faculty of Chemistry, Biology and Geography, Department of Biology, 16A Pestalozzi, 300115, Timisoara, Romania

\begin{abstract}
The paper presents the preliminary results obtained in a study aimed to assess the level of air pollution with heavy metals in urban areas by means of using bioindicators. The tests were carried out in one of the most polluted cities in western Romania, using as bio-indicators corticolous lichens collected from seven representative sites for air quality in the city. The assessment level of air pollution with heavy metals ( $\mathrm{Cd}, \mathrm{Ni}, \mathrm{Pb}, \mathrm{Cu}, \mathrm{Mn}, \mathrm{Zn}, \mathrm{Cr}$ ) was based on the effect that their presence could induce on lichens. Thus, two methods were used for the quantification of the effect such as: a) IAP method, variation in diversity and abundance - calculation of the value of Index of Atmospheric Purity, IAP and b) determining the content of heavy metals in the lichen thalli, respectively. Classification of air quality from the seven sampling sites in pollution classes (low pollution, moderate pollution, high pollution and very high pollution) was based on the statistical tests for correlation between the metal concentration in the air and the specific parameters for the two evaluation methods (the IAP index value for the first method and the metals concentration in the lichen thalli for the second method). The tests results revealed a differentiated air quality in the seven sites, also indicating the method of biomonitoring with corticolous lichens as a viable option for assessing the air quality in polluted areas with heavy metals.
\end{abstract}

Keywords: air pollution, biomonitoring, heavy metals, IAP, lichens

\section{Introduction}

Lichens are organisms resulting from the symbiosis of a green algae or a cyanobacteria and a fungus. They are a very widespread group of plants around the world, growing on any substrate (wood, earth, trees, stones, rocks, etc.) and under the most unfavourable conditions, so they were named "pioneers of vegetation".

Air pollution from urban centres and around them reaches concentrations that are large enough to have a damaging effect on vascular plants.

Lichens accumulate very efficiently minerals and pollutants, they grow slowly and live for a long time and, therefore, can accumulate large amounts of toxic substances over a long period of time while other types of plants usually remove large areas of loaded leaves with toxins every year (Johnson 1979). 


\section{INTERNATIONAL SYMPOSIUM "THE ENVIRONMENT AND THE INDUSTRY", SIMI 2018, PROCEEDINGS BOOK}

When they are hydrated, lichens absorb nutrients and contaminants all over the surface. During dehydration, nutrients and many contaminants, concentrate by absorbing on cell walls, inside cellular organisms, or crystallize before cells (Nieober et al 1978).

Characterization of the chemical composition of atmospheric deposits is relevant for the assessment of ambient air quality by providing information on the origin of atmospheric pollutants (natural or anthropogenic), regional and long-distance transport, and impacts on ecosystems (Petrescu et al 2017). Traffic arteries are known to be contaminated with heavy metals emitted by the exhaust gases of motor vehicles after combustion of fuels. It is well known that pollution of the natural environment with heavy metals is an universal problem because these metals are not biodegradable and many of them have toxic effects on micro and macro organisms and implicitly on human health (Kim et al 2017).

The current study aimed to quantify heavy metals in the atmosphere by unconventional methods (use of corticolous lichens) other than those already existing. Our study was conducted in July 2017.

\section{Materials and Methods}

Study area

The study area of the present paper was Timisoara, one of the largest cities in Romania, located in the Western Plain. According to the 2011 census, the city has 319,279 inhabitants and an area of $130.5 \mathrm{~km}^{2}$ (National Institute of Statistics 2017), being the third largest city in Romania. This makes Timisoara an important industrial centre which also leads to considerable pollution level of the environment with various compounds. In addition to industrial pollution, the urban agglomeration contributes to an augmentation of pollution with heavy metals resulting from mainly by heavy traffic, which is a growing problem in large and crowded cities in Romania.

Seven sampling sites were selected at a distance of $~ 2-3 \mathrm{~km}$ from each other on the $\mathrm{N}-\mathrm{S}$ axis as a study area (Figure 1). The influence of the road traffic on the lichenological flora and the degree of accumulation of heavy metals in thallus were considered. Sites 1 and 2 were not directly influenced by road traffic, sites 4 and 5 indicated a medium traffic, sites 3 and 6 were characterized by heavy traffic, and site 7 highlighted very heavy traffic.

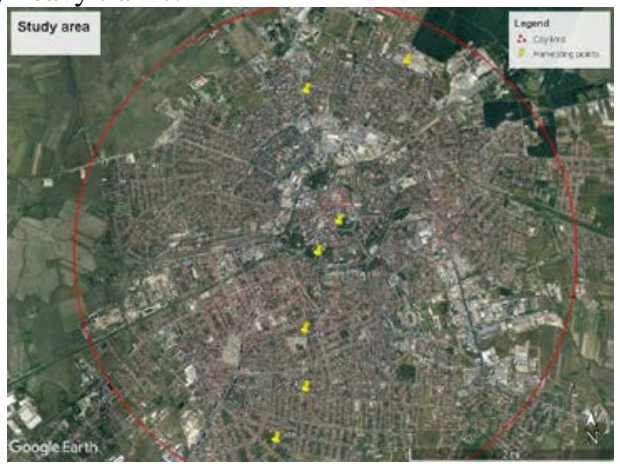

Figure 1. Satellite view of the study area - Timisoara and the seven sampling sites. 


\section{INTERNATIONAL SYMPOSIUM "THE ENVIRONMENT AND THE INDUSTRY", SIMI 2018, PROCEEDINGS BOOK}

In order to compare the heavy metals concentrations in lichen species harvested from Timisoara with reference values from unpolluted areas, a control sample was used: a lichen sample was collected from a forest area located at $70 \mathrm{~km}$ northeast of Timisoara (Figure 2). This area was considered as one with low pollution.

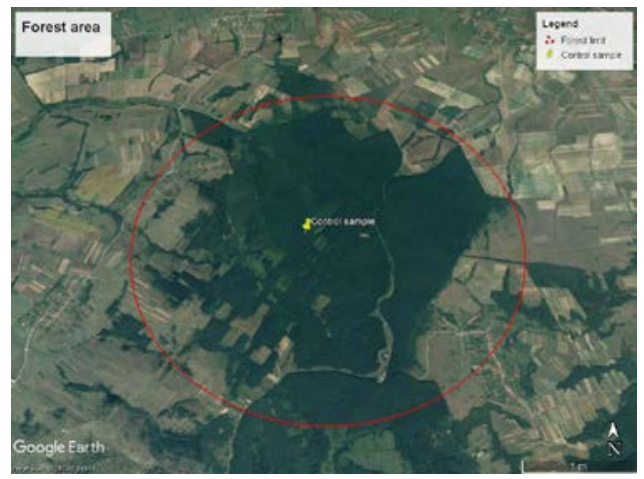

Figure 2. Satellite view of the control sample area.

\section{Index of Atmospheric Purity (IAP)}

In July 2017, for each site, lichens were sampled from 2-4 trees with a distance of at least $100 \mathrm{~m}$. The identification of lichen species and the quantification of individuals of each species was carried out on an imaginary surface of 20x20 cm metric scale, across the entire circumference of the tree at 1-1.5 $\mathrm{m}$ from the ground. This distance from the ground was used to avoid the influence of soil and precipitation water that washed the road and came to the bottom of the trees. After this procedure, the lichens were inserted into plastic bags and transferred to the laboratory to determine the existing species.

Based on the number of individuals of each species on each studied tree, a scale of measurement of the coverage abundance was proposed by us, starting from the scale proposed by Braun-Blanquet (Stringer \& Stringer 1974): $2=1-10$ individuals, $3=$ $11-20$ individuals, $4=21-40$ individuals, $5=41-70$ individuals, $6=71-100$ individuals.

The degree of atmospheric pollution of each site was determined using the formula of Index of Atmospheric Purity (IAP) proposed by LeBlanc and DeSloover (1970)

$$
I A P=\Sigma(Q \times F) / 10
$$

where" $Q$ ” is the association index for each species and " $F$ " represents the sum of the abundance values for each species, according to the used scale.

The "Q" value for each species represents the sum of the species in each site where the species are found and the resulting amount is divided by the number of sites where the species referred to were present.

The number of individuals of crustose thalli species were could not be identified and thus, the values for "F" were based on visual appreciation. 


\section{INTERNATIONAL SYMPOSIUM "THE ENVIRONMENT AND THE INDUSTRY", SIMI 2018, PROCEEDINGS BOOK}

Determining the accumulation of heavy metals in the lichen thalli

Additional analysis of the abiotic factors affecting the lichenological communities was necessary to identify the stress related to the decrease of lichen biodiversity. For this reason, a spectrophotometric analysis was carried out to determine the content of heavy metals in the lichen thalli (Cd, Ni, Pb, $\mathrm{Cu}, \mathrm{Mn}, \mathrm{Zn}, \mathrm{Cr}$ ). For this, the lichen thallus was thoroughly washed with distilled water and dried in the oven at $105^{\circ} \mathrm{C}$ (Labtech, South Korea) to determine the dry matter. From 0.25 to $0.50 \mathrm{~g}$ dry tissue was weighed and calcined at $550^{\circ} \mathrm{C}$ (Daihan Labtech CO-LTD, South Korea). The ash was digested with a mixture of $\mathrm{HCl}+\mathrm{HNO}_{3}$ 3:1 (aqua regia). The crucible was washed three times with $3 \mathrm{ml}$ of $\mathrm{HCl}$ 1:1. The solutions to take over the residue and the solutions for washing were filtered through paper Sartorius filter papers 2-206 FT and quantitative moved in $25 \mathrm{ml}$ flasks (rated baloon). They were filled to the mark with the $\mathrm{HCl}$ 1:1. Determination of metals was carried out with a spectrophotometer Avanta AAS type (GBC Scientific Equipment Pty Ltd, Australia).

\section{Results and Discussion}

The values of the Index of Atmospheric Purity for each site, were presented in Figure 3. Low IAP values indicated areas with high atmospheric pollution, and high IAP values indicated areas with improved air quality.

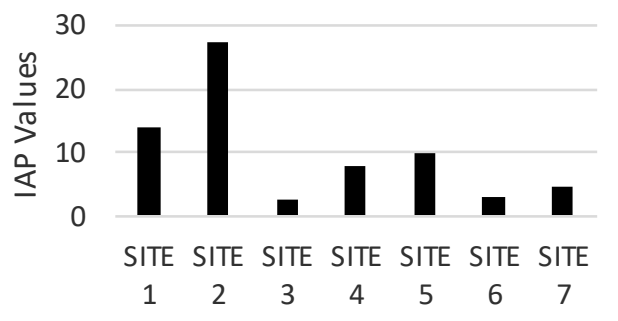

Figure 3. IAP values for each site from Timisoara in July 2017.

The different values of the IAP were used to divide the study area into 4 sub-zones as follows: zone I includes sites with IAP values between $0-5$ (very high pollution); zone II= 6-10 (high pollution); zone III= 11-20 (moderate pollution) and zone IV= 21-30 (low pollution). Table 1 showed the results of IAP values at each site and the corresponding pollution degree.

Table 1. The grading of sites in the pollution sub-zones, based on IAP values

\begin{tabular}{c|cccc}
\hline Sub-zone & $\begin{array}{c}\text { I (very high } \\
\text { pollution) }\end{array}$ & $\begin{array}{c}\text { II (high } \\
\text { pollution) }\end{array}$ & $\begin{array}{c}\text { III (moderate } \\
\text { pollution) }\end{array}$ & $\begin{array}{c}\text { IV (low } \\
\text { pollution) }\end{array}$ \\
\hline Site & $3,6,7$ & 4,5 & 1 & 2 \\
\hline
\end{tabular}

Moreover, the total amount of heavy metals determined in lichen thallus for each site were presented in Table 2. 


\section{INTERNATIONAL SYMPOSIUM "THE ENVIRONMENT AND THE INDUSTRY", SIMI 2018, PROCEEDINGS BOOK}

Table 2. Quantitative results of heavy metals detected in lichen thallus from the 7 sites from Timisoara

\begin{tabular}{|c|c|c|c|c|c|c|c|c|}
\hline \multirow{2}{*}{ Site } & \multirow{2}{*}{$\begin{array}{c}\text { Total amount } \\
\text { [mg/kg d.m.] }\end{array}$} & \multicolumn{7}{|c|}{ Concentrations of heavy metals [mg/kg d.m.] } \\
\cline { 3 - 9 } & & $\mathrm{Ni}$ & $\mathrm{Zn}$ & $\mathrm{Mn}$ & $\mathrm{Cu}$ & $\mathrm{Pb}$ & $\mathrm{Cd}$ & $\mathrm{Cr}$ \\
\hline \multirow{2}{*}{ Site 1 } & 175 & 3.50 & 115 & 34.6 & 15.3 & 6.60 & $<0.11$ & $<0.13$ \\
Site 2 & 151 & 4.00 & 87.1 & 37.5 & 21.3 & 1.00 & $<0.11$ & $<0.13$ \\
Site 3 & 314 & 3.90 & 210 & 79.6 & 15.2 & 5.00 & $<0.11$ & $<0.13$ \\
Site 4 & 317 & 9.50 & 218 & 66.5 & 22.2 & 0.500 & $<0.11$ & $<0.13$ \\
Site 5 & 149 & 6.00 & 74.8 & 46.5 & 16.9 & 4.80 & $<0.11$ & $<0.13$ \\
Site 6 & 205 & 3.60 & 103 & 69.8 & 17.2 & 11.1 & $<0.11$ & $<0.13$ \\
Site 7 & 469 & 9.00 & 296 & 77.0 & 83.2 & 4.00 & $<0.11$ & $<0.13$ \\
Control & 159 & 1.60 & 47.7 & 97.0 & 3.60 & 8.22 & $<0.11$ & $<0.13$ \\
sample & & & & & & & & \\
\hline
\end{tabular}

d.m.=dry matter

Table 2 indicate that $\mathrm{Zn}, \mathrm{Mn}$ and $\mathrm{Cu}$ were found in the largest proportion in the lichen thalli. The presence of zinc in the control site may be explained by the use of fungicides and fertilizers containing $\mathrm{Zn}$ in the forest boundary area. In addition, the presence of $\mathrm{Zn}$ in the urban areas might be a consequence of cars evacuation and tire wear. The large amount of $\mathrm{Cu}$ in the urban environment was also an effect of diesel and unleaded gasoline, these being the main sources of atmospheric $\mathrm{Cu}$. The use of $\mathrm{Cu}$-containing products, such as fungicides in agriculture could be a possible source of $\mathrm{Cu}$ in lichens in the control site.

Manganese is an abundant element in the lithosphere, and the appearance of this element in the lichen thalli was derived at least partially from the upper layer of wind-blown soil. Besides of this natural contamination, the presence of manganese in high concentrations may also be caused by the abrasion of motor vehicles, due to the fact that they release heavy metal particles into the atmosphere (Affum 2008).

Lead was described as a major toxic metal that causes multiple effects on human health such as adrenal insufficiency, cardiovascular disease, hypertension, Parkinson's disease etc. (Goyer \& Clarkson 2001), so it is very important to know the level of lead in the atmosphere, and lichens can give indications of the presence of this element in the atmosphere. Lichens are highly efficient Pb-accumulation through aerosols, leakage of metal particles or acid rain (Cervantes et al 2008).

The values obtained for nickel were compared to those reported by Loppi (Loppi et al 1994) for the centre of Italy. He reports values between 1.19 and $4.59 \mu \mathrm{g} / \mathrm{g} \mathrm{d.m.}$ which are similar to those determined by us.

Cadmium and chromium had values below the detection limit of the method.

It was evident, however, that besides the anthropogenic sources heavy metal contamination, their presence in lichens was also determined, at least partially, by natural causes, and this was confirmed by the presence of heavy metals in the control sample.

Considering the total amount of metals detected in the lichen thalli, it was possible to divide the study area into 4 sub-zones with different degrees of atmospheric pollution (Table 3). Zone I= 100-200 mg/kg d.m. (low pollution); Zone II= 201-300 $\mathrm{mg} / \mathrm{kg}$ d.m. (moderate pollution); Zone III= 301-400 mg/kg d.m. (high pollution); Zone IV $=\geq 401 \mathrm{mg} / \mathrm{kg}$ d.m. (very high pollution). 
Table 3. The grading of sites in the pollution sub-zones, based of heavy metals amount

\begin{tabular}{c|cccc}
\hline Sub-zone & I (low pollution) & $\begin{array}{c}\text { II (moderate } \\
\text { pollution) }\end{array}$ & $\begin{array}{c}\text { III (high } \\
\text { pollution) }\end{array}$ & $\begin{array}{c}\text { IV (very high } \\
\text { pollution) }\end{array}$ \\
\hline Site & $\begin{array}{c}1,2,5, \\
\text { control sample }\end{array}$ & 6 & 3,4 & 7 \\
\hline
\end{tabular}

Correlation of the two methods presented with reference values in the air

In order to achieve the study goal represented by the correlation of corticolous lichens results with the intensity of air pollution measured from fraction PM10 of the particles in suspension, the National Environmental Protection Agency (NEPA) public database was used. In Timis County, there were six automatic stations, out of which four in Timisoara. The quantification of heavy metals (only lead and nickel) was done in three stations: TM1, TM2 and TM5. The analysis measured at the three automatic stations as well as the lichen analysis for all sampling points, was noted a good overlapping. Each sampling site was located near an automatic station: TM 1 station (Timisoara South) - site 3; site 4; site 5; TM 2 station (Timisoara Center) site 1; site 2; TM 5 station (Timisoara North) - site 6; site 7.

No mathematical relationship was established between the air quality determined by the instrumental analysis and the two methods analysed in the present study, therefore a conventional air quality assessment scale was introduced taking into account the average annual values for 2017 from National Environmental Protection Agency database: TM 1 - increased intensity; TM 2 - medium intensity; TM 5 - low intensity.

The correlation between the results of air quality surveillance network and the grading of sites according to heavy metals concentration, as well as IAP was presented in Table 4.

Table 4. Correlation between the classification of the pollution level according to heavy metal concentrations and indicator IAP and NEPA database

\begin{tabular}{|c|c|c|c|}
\hline $\begin{array}{c}\text { Harvesting } \\
\text { area }\end{array}$ & $\begin{array}{l}\text { Grading according to } \\
\text { heavy metals in the thallus }\end{array}$ & $\begin{array}{l}\text { Grading according to } \\
\text { IAP values }\end{array}$ & $\begin{array}{l}\text { Grading according to } \\
\text { NEPA network }\end{array}$ \\
\hline Site 1 & Low pollution & Moderate pollution & Medium intensity \\
\hline Site 2 & Low pollution & Low pollution & Medium intensity \\
\hline Site 3 & High pollution & Very high pollution & Increased intensity \\
\hline Site 4 & High pollution & High pollution & Increased intensity \\
\hline Site 5 & Low pollution & High pollution & Increased intensity \\
\hline Site 6 & Moderate pollution & Very high pollution & Low intensity \\
\hline Site 7 & Very high pollution & Very high pollution & Low intensity \\
\hline
\end{tabular}

The three harvesting areas in the south of the municipality (site 3, site 4, site 5), and the sites in the central area (site 1 and site 2), an acceptable correlation was observed. For the other two sites it was not possible to make a accurate correlation, based on the frames presented above, because these areas do not present a constant and uniform pollution, these areas being influenced mainly by the road traffic. The area located in the south of the city was likely to have a constant pollution, but considering the ability of lichens to accumulate and store heavy metals over several 


\section{INTERNATIONAL SYMPOSIUM "THE ENVIRONMENT AND THE INDUSTRY", SIMI 2018, PROCEEDINGS BOOK}

years, this bio-indicators might be used as warning system in air pollution assessment studies.

\section{Conclusions}

In the present study, the intensity of air pollution was assessed in seven sampling sites located on the north-south axis of Timisoara. Both the Index of Atmospheric Purity and the metals concentrations in the lichen thallus were calculated, based on which, an evaluation scale was made by 4 levels of pollution intensity (low, moderate, high and very high pollution).

The highest quantities of heavy metals were recorded in heavy and very heavy traffic areas, and the lowest values were presented in the areas that were not directly affected by road traffic. The heavy metals with the highest concentrations detected in the thallus were zinc, copper and manganese. The presence of these metals was mostly caused by road traffic, which signals the existence of a growing problem for highly developed cities from Romania.

Some of the study results were correlated with the National Environmental Protection Agency data, about heavy metals detected in the air (lead and nickel). The experiments carried out in the present study, lead to the conclusion that the analytical experiments, both the heavy metal detection method and the method using the IAP indicator, could be used as low cost alternatives for assessing air pollution in areas with constant pollution. Moreover, using the IAP indicator, heavy metal pollution can be determined through the mathematical formula based on species abundance, the formula that does not involve any chemical analysis.

Therefore, the experimental study validated the fact that lichens were good bioindicators of heavy metals in the air, and they can be used for the identification of heavy metals in the air samples.

\section{Acknowledgements}

The present research was financially supported by the Romanian Nucleu Programme, Project PN 16250116.

\section{References}

Affum, HA, Oduro-Afriyie, K, Nartey, VK, Adomako, D \& Nyarko, BJB 2008, 'Biomonitoring of airborne heavy metals along a major road in Accra', Environmental Monitoring and Assessment, vol. 137, pp. 15-24.

Cervantes, L, Ávila, O, Ruvalcaba, JL, Miranda, J \& Muñoz, R 2008, 'The use of biomonitors and PIXE analysis in the study of air pollution in Mexico City', $X$ Ray Spectrometry, vol. 37, pp. 156-62.

Goyer, RA \& Clarkson, TW 2001, 'Casarett and Doull's toxicology: the basic science of poisons', McGra w-Hill Education, New York.

Johnson, DW 1979, 'Air pollution and the distribution of corticolous lichens in Seattle, Washington', Northwest Science, vol. 53, no. 4, pp. 257-263.

Kim, L, Muresan, A-M, Cuciureanu, A, Guta, D, Arama, M, Cristea, NI \& Dediu, V, 2017, 'Experimental models of characterization and analysis of industrial waste', 20 ${ }^{\text {th }}$ International Symposium "The Environment and The Industry",SIMI 2017, National Research and Development Institute for Industrial Ecology ECOIND, Bucharest, pp. 142-150. 


\section{INTERNATIONAL SYMPOSIUM "THE ENVIRONMENT AND THE INDUSTRY", SIMI 2018, PROCEEDINGS BOOK}

LeBlanc, F \& DeSloover, J 1970, 'The relation between industrialization and the distribution and growth of epiphytic lichens and mosses in Montreal', Journal of Botany, vol. 48, pp. 1485-1496.

Loppi, S, Chiti, F, Corsini, A \& Bernardi, L 1994, 'Lichen biomonitoring of trace metals in the Pistoia area (central northern Italy)', Environmental Monitoring and Assessment, vol. 29, no.1, pp. 17-27.

Nieober, E, Richardson, DHS, Tomasini, FD 1978, 'Mineral uptake and release by lichens: an overview', Bryologist, vol. 81, no. 2, pp. 226-246.

National Institute of Statistics. Available from: http://www.insse.ro/cms/ [14 June 2017].

Petrescu, M, Bucur, E, Diodiu, R, Bratu, M, Serbanescu, A \& Barbu, M 2017, 'Chemical characterization of wet depositions in urban and rural area', 20 th $20^{\text {th }}$ International Symposium "The Environment and The Industry", SIMI 2017, National Research and Development Institute for Industrial Ecology ECOIND, Bucharest, pp. 213-220.

Stringer, PW \& Stringer, MHL 1974, 'Air pollution and the distribution of epiphytic lichens and bryophytes in Winnipeg, Manitoba', The Bryologist, vol. 77, pp. 405-426. 